\title{
Time-Series Displacement of Land Subsidence in Fuzhou Downtown, Monitored by SBAS-InSAR Technique
}

\author{
Bo Hu $(\mathbb{D}$, Bin Yang $(\mathbb{D}$, Xingfu Zhang, Xiongle Chen, and Yang Wu \\ Guangdong University of Technology, Guangzhou, China \\ Correspondence should be addressed to Bo Hu; hubo@asch.whigg.ac.cn and Bin Yang; 598725908@qq.com
}

Received 15 February 2019; Revised 5 April 2019; Accepted 28 April 2019; Published 19 May 2019

Guest Editor: Lei Zhang

Copyright ( 2019 Bo Hu et al. This is an open access article distributed under the Creative Commons Attribution License, which permits unrestricted use, distribution, and reproduction in any medium, provided the original work is properly cited.

\begin{abstract}
The land subsidence in response to the construction of underground engineering, e.g., subway, has caused many geological hazards and impeded the sustainable development of urbanization, in particular of China. Analysis of land subsidence with high temporalspatial resolution is necessary and can help to assess the risk of geohazards. In this study, we apply the SBAS-InSAR technique to monitor the land subsidence in Fuzhou downtown after the program of metro construction. 24 scenes of X-band TerraSAR data from July 2013 to August 2015 and 32 scenes of C-band Sentinel-1 data from July 2015 to February 2018 were used in this experiment. Our results show a maximum subsidence rate of $-12 \mathrm{~mm} / \mathrm{yr}$, and eight subsidence funnels have been found during the observed period. After analyzing the subsidence of these regions in a long time span, it can be concluded that there are three regions which have a relatively stable disastrous subsidence effect, and there is a possibility of further intensified subsidence.
\end{abstract}

\section{Introduction}

Fuzhou, as the provincial capital of Fujian, China, has made an aggressive effort in expanding its urban construction engineering. As of 2018, the Fuzhou city has undergone major expansions:

(1) Line 1 started construction on December 27, 2009. It has a total length of 28.8 kilometers and is connected to the central area of Jinan, Drum Tower, Taijiang and Cangshan.

(2) Line 2 started construction on November 28, 2014, and is still under construction.

The rapid development of underground engineering has also caused many negative impacts, such as land subsidence, soil erosion, building collapse, and underground pipeline rupture. Land subsidence is one of the main hazards of engineering construction. Urban land subsidence is a worldwide problem, and many cities in the world are endangered by land subsidence [1]. Land subsidence disasters will lead to changes in ground elevation, damage to municipal facilities and buildings, and threat to the safety of railway transportation, thus affecting the development and security of the city [2]. For the prevention and control of the impact and damage caused by land subsidence, it is urgent to establish an effective urban subway construction project area deformation monitoring and early warning system. In the field of subway construction engineering in densely populated commercial blocks, deformation monitoring technology is proposed to meet the requirements of high precision, high efficiency, and full time coverage.

At present, the monitoring methods and techniques of traditional ground settlement mainly include highprecision traditional leveling, hierarchical dynamic monitoring (bedrock, stratification, groundwater dynamic monitoring), and GPS measurement technology. However, with the rapid development of urban construction, the scope of settlement has been continuously expanded and the network layout problem has been monitored, which has led to an increase in measurement difficulty: leveling point coverage gap, long measurement cycle, and waste of manpower and material resources; hierarchical dynamic monitoring of construction site is difficult to choose, one-time investment of a large amount of funds and limited outlets cloth; GPS measurement points are easily damaged and difficult to maintain.

In recent years, Interferometric Synthetic Aperture Radar (InSAR) technology, having the advantages of being weatherindependent and having high ground sensitivity, has received extensive attention in ground deformation measurement [3]. 
In general, Differential InSAR (D-InSAR) technology firstly generates an interferogram containing both surface deformation information and terrain information from two radar images through traditional InSAR technology and then inverts the terrain phase based on the external DEM and removes it from the interference phase [4-7]. Finally, an interferogram containing only topographical deformation information is obtained, but, in fact, the interferogram also has an atmospheric phase effect, making it difficult to achieve high-precision measurement $[8,9]$.

In order to solve the atmospheric phase effect, the scholars have conducted in-depth research and development on Permanent Scattering InSAR (PS-InSAR) [10, 11] and Small Baseline Subset InSAR (SBAS-InSAR) [12]. Among them, the SBAS-InSAR technology performs a suitable combination of the acquired data to obtain a series of small baseline subsets of differential interferograms, which can better overcome the atmospheric phase effects. Then the singular value decomposition (SVD) method is used to solve the deformation rate and solve the problem of rank loss in the solution process [13].

Urban areas are susceptible to surface deformations caused by many factors, such as nature and human activities. In 2012, Xu Wenbin used SBAS-InSAR technology combined with GPS data and groundwater level data to study the surface time series deformation in Los Angeles, USA, and successfully revealed the surface deformation of the area from 2003 to 2009 [14]. In addition, in 2014, Estelle Chaussard used ALOS data for time series deformation studies, analyzed land subsidence problems throughout Mexico City through SBAS-InSAR technology, and successfully identified land subsidence in 21 regions (including 17 cities). Mexico City has a linear vertical speed of more than $30 \mathrm{~cm} /$ year, while other places detect a speed of 5-10 cm/year [15]. Similarly, Shaochun Dong used SBAS-InSAR to perform time series deformation analysis of Shanghai ground subsidence. The results showed that most of the study area sank evenly, but along the subway lines, elevated roads and highways, the skyscrapers quickly subsided around them [2].

In summary, although relevant scholars have proved the scientific reliability of InSAR technology on urban ground deformation, the relevant research results are mostly shortterm deformation monitoring based on single-satellite InSAR technology, and it is difficult to continuously monitor the construction process with high precision.

In this research, two different radar satellite data, TerraSAR and Sentinel-1A, performed long-term surface deformation monitoring for Fuzhou downtown from 2013 to 2018, increasing the monitoring frequency and expanding the monitoring range. Combined with the construction of Fuzhou subway construction and related disaster information, the results of surface deformation during the construction of Fuzhou subway were studied to evaluate the feasibility and practicability of SBAS-InSAR technology in urban building deformation monitoring and to prove that this technology can be one of the convenient and effective monitoring methods in the construction and maintenance of urban buildings.

\section{Study Area and Dataset}

2.1. Study Area. The study area is located in the core area of Fuzhou downtown in Fujian province (Gulou District, Jinan District, Taijiang District, Cangshan District); these areas are with dense high buildings, large population flow, complex geological conditions, and traffic facilities. The main construction and operation of line 1 and line 2 were carried out during this period. The addition to focusing on the areas where the two metro lines pass through, the study also concerned on the urban areas affected by various large-scale urban construction engineering. The coverage of radar image data is shown in Figure 1.

2.2. Data. External DEM data, the "ALOS World 3D-30m" data with a spatial resolution of 30 meters provided by the Japan Aerospace Agency (JAXA), is used to simulate and eliminate terrain phase contributions. The DEM data is also used to reshape and geocode the resulting InSAR product from the running Ge-Doppler coordinates to the map geometry corresponding to the Universal Transverse Mercator (UTM) coordinate system.

In this research, 24 scene TerraSAR-X images and 32 scene Sentinel-1A images were selected as research data sources. The former covers July 18, 2013, to August 27, 2015, and the latter covers the period from July 6, 2015, to February 8, 2018.

Based on the selection principle of short baseline set, the optimal space baseline value and the optimal time baseline value are established, which not only ensures the continuity of time and space interference, but also ensures the correlation of interference results. The spatial baseline value of this experiment was $0-600 \mathrm{~m}$, and the time baseline value was 0 200 days. The system automatically selects the super-master image in the master image in the small baseline subset according to the three-baseline minimum principle (spatial baseline, time baseline and Doppler centroid frequency baseline). Finally, 62 pairs of effective interference pairs were obtained between July 18, 2013, and August 27, 2015. 162 pairs of effective interference pairs were obtained between July 6 , 2015, and February 8, 2018 (see Figure 2).

\section{Method and Data Processing}

SBAS-InSAR is a newly developed D-InSAR time series analysis method, first proposed by Berardino et al. [16]. It combines all the acquired SAR data to form interference pairs and then sets the spatial baseline and time baseline threshold and obtains several small baseline sets whose spatiotemporal baseline is smaller than the threshold. The surface deformation time series of each set can be solved by the least square method, and then several singular baseline sets are solved by singular value decomposition (SVD). This effectively solve the different small baseline between sets due to baseline caused by the long time discontinuity problem, improve the monitoring time resolution, effectively solve the general equation rank deficient problem, and finally get the sequence covering the whole observation time of ground subsidence. 


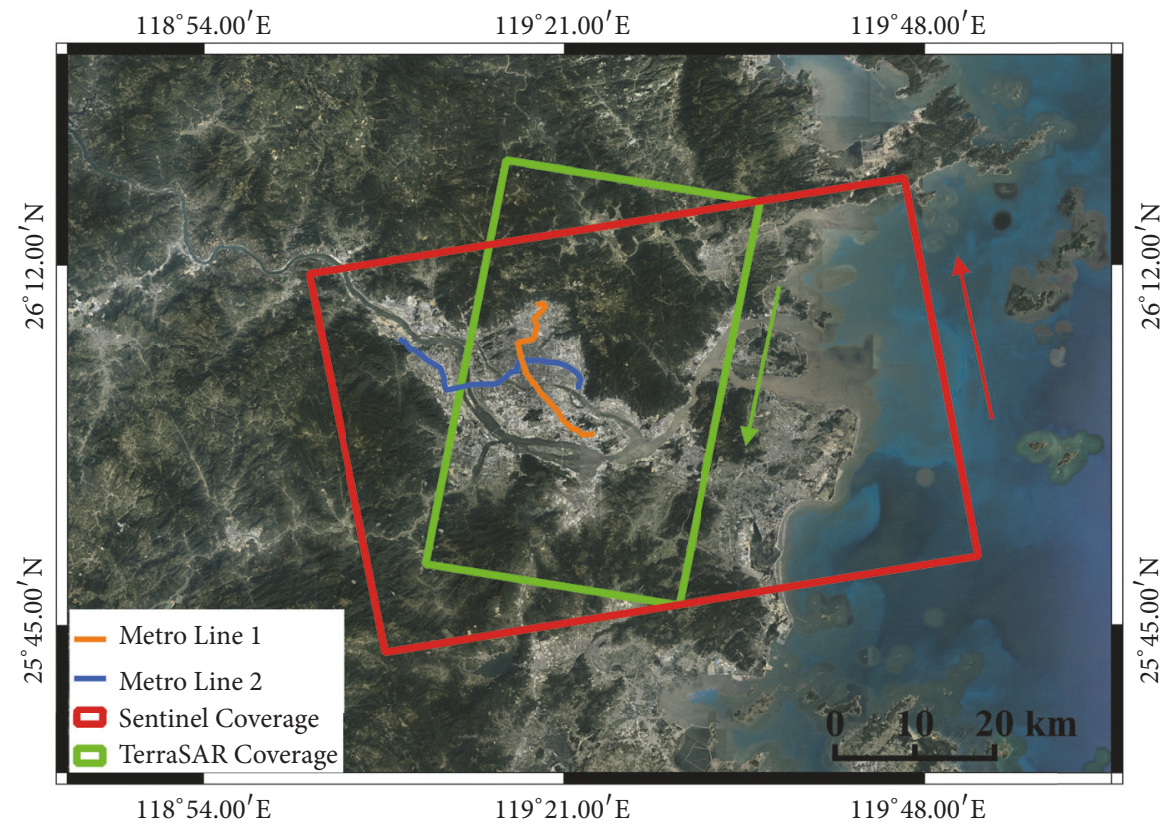

FIGURE 1: The coverage of the radar image used in this research overlaid on Fuzhou administrative map.

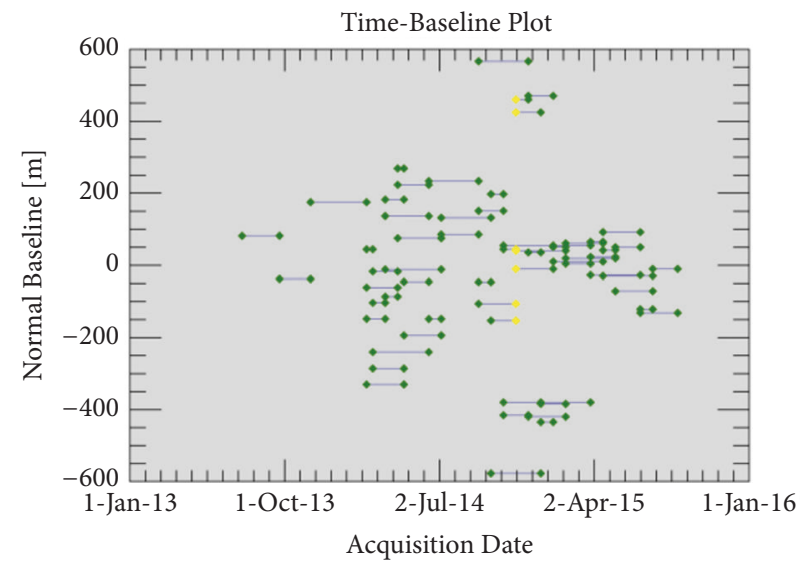

(a)

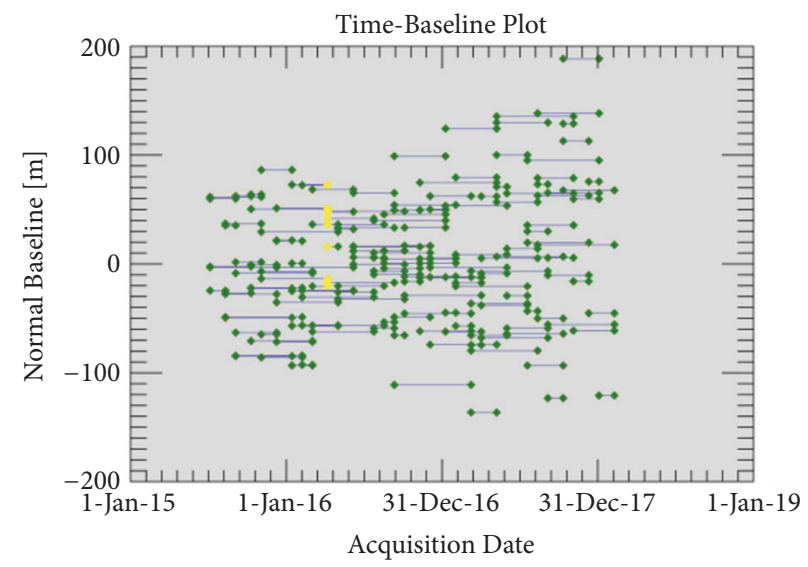

(b)

FIGURE 2: Time-baseline and time-position plots relevant to the radar images and interferograms used in this study. (a) refers to the TerraSARX (201307-201508) and (b) refers to the Sentinel-1(201507-201802).

Assuming that the SAR image in the same area is $\mathrm{N}+1$, the time of shooting is $t_{0}, t_{1}, t_{2}, t_{3}, \ldots . . t_{n}$; at least it is combined into $\mathrm{M}$ interference fringe images.

For any two differential interference diagrams $\left(t_{a}<t_{b}\right)$, the unwrapped phase can be expressed as [17]:

$$
\begin{aligned}
\delta \phi_{x, i} & =\phi_{x, i}\left(t_{b}\right)-\phi_{x, i}\left(t_{a}\right) \\
& =\phi_{\text {flat }, x, i}+\phi_{\text {ele }, x, i}+\phi_{\text {disp }, x, i}+\phi_{\text {atm }, x, i}+\phi_{\text {noise }}
\end{aligned}
$$

In formula (1), $\delta \phi_{x, i}$ is the i image and the interference phase of the $\mathrm{x}$ pixel. $\phi_{x, i}\left(t_{b}\right)$ and $\phi_{x, i}\left(t_{a}\right)$ is the phase of interference at two different times.
The $\phi_{\text {flat }, x, i}$ is the phase difference of the flat phase, the $\phi_{e l e, x, i}$ is the phase difference of terrain phase, the $\phi_{\text {disp }, x, i}$ is the phase difference of ground deformation, the $\phi_{a t m, x, i}$ is the error of atmospheric phase, and $\phi_{\text {noise }}$ is the error of noise.

The flat phase, the phase of the terrain, the phase of the deformation, and the phase of the atmosphere in the formula (1) can be further expressed as

$$
\begin{aligned}
\phi_{\text {flat }, x, i} & =-\frac{4 \pi}{\lambda} \frac{B_{n}}{R \tan \theta} \\
\phi_{\text {ele }, x, i} & =-\frac{\Delta q}{\sin \theta} \frac{B_{n}}{R} \frac{4 \pi}{\lambda}
\end{aligned}
$$




$$
\begin{aligned}
& \phi_{\text {disp }, x, i}=\frac{4 \pi}{\lambda}\left[d\left(t_{b}, x, i\right)-d\left(t_{a}, x, i\right)\right] \\
& \phi_{a t m, x, i}=\phi_{a t m}\left(t_{b}, x, i\right)-\phi_{a t m}\left(t_{a}, x, i\right)
\end{aligned}
$$

In the formula, $\lambda$ is the radar wavelength and $\mathrm{R}$ is the slope distance, $B_{n}$ is the vertical baseline, $\Delta \mathrm{q}$ is the DEM elevation difference, and $\theta$ is the incidence angle.

Suppose the deformation rate between two different interferograms is $V_{i}(\mathrm{i}=1, \ldots, \mathrm{n})$, then the cumulative deformation between $t_{a}$ and $t_{b}$ can be expressed as [18]

$$
\phi_{\text {disp } x, i}=\frac{4 \pi}{\lambda} \sum_{i=t_{a}}^{t_{b}} V_{i, i+1}\left(t_{i+1}-t_{i}\right)
$$

The integral of the deformation rate is in the time interval between the master and slave images of the interferogram.

Immediately the integration of speed is at each time interval between master image and slave image intervals. Written in matrix form:

$$
\mathrm{BV}=\delta \phi
$$

By using the SVD method, a generalized inverse matrix of the coefficient matrix B can be obtained, so that the minimum norm solution of the data vector can be obtained. Finally, the speed integral for each time period gives the amount of deformation for each time period.

\section{Result}

According to SBAS-InSAR technology, the annual average settlement map of Fuzhou city from July 2013 to August 2015 and from July 2015 to February 2018 was obtained (see Figure 3), and the time series settlement displacement is shown in Figure 4. From the results, it can be found that there are a large number of discrete results and some abnormal uplift areas in the north of the city. This is because there are a large number of vegetation areas in the area. The growth and withering of plants tends to lead to low coherence or even complete decorrelation, which leads to unwrapping error and even unable to unwrapping. In addition, eight different large subsidence areas can be found (named I VIII area in order, and the approximate settlement position and range are divided by two-year average settlement).

After statistical analysis of the annual average settlement rate map at two different time periods, the average annual rate of Fuzhou downtown from 2013 to 2015 is $+1.32 \mathrm{~mm} /$ year, the average annual rate is between $123 \mathrm{~mm} /$ year and $+103 \mathrm{~mm} /$ year, and the standard deviation among all pixel values is $\pm 9.0 \mathrm{~mm} /$ year. From 2015 to 2018 , the average annual rate is $-3.7 \mathrm{~mm} /$ year, the average annual rate is $-120 \mathrm{~mm} /$ year to $+80 \mathrm{~mm} /$ year, and the standard deviation was $\pm 10 \mathrm{~mm} /$ year.

It can be seen that the entire Fuzhou is in stable state from 2013 to 2018. The standard deviations of the results of the two data sources are very close, which proves that the monitoring accuracy of the two data sources is also very good. In addition, the subsidence area is basically located near the subway line, and it is speculated that the construction and operation of the subway has a huge impact on the land subsidence in Fuzhou.

The interval value of the deformation point rate along the subway is calculated by the interval method. Taking the geographical location of two different subway stations as the center of the left and right boundaries of the interval, the range of influence of the selection interval is 100 meters. The rate of all the deformation points in the statistical interval is worth the average rate value of each interval of line 1 and line 2 in different periods. According to engineering geological experience, areas with deformation rate values between $5 \mathrm{~mm} /$ year and $+5 \mathrm{~mm} /$ year in urban areas can be regarded as relatively stable areas, while deformation areas exceeding $\pm 5 \mathrm{~mm} / \mathrm{y}$ years are classified as potential disaster areas. Based on the above statistical principle, the regional average rate value is obtained by counting the deformation point velocity values in the I to VIII region. The settlement rates for the first to sixth districts from 2013 to 2015 are $-7 \mathrm{~mm} /$ year, -5.5 $\mathrm{mm} /$ year, $-6.7 \mathrm{~mm} /$ year, $-5.2 \mathrm{~mm} /$ year, $-8.2 \mathrm{~mm} /$ year, and $12.2 \mathrm{~mm} /$ years, while the V, VII, and VIII zones reach -8.7 $\mathrm{mm} /$ year, $-5.4 \mathrm{~mm} /$ year, and -7 and from 2015 to $2018,4 \mathrm{~mm}$ per year (Zones I, II, III, VII, and VIII belong to Metro Line 2; Area IV belongs to Metro Line 1; Areas V and VI are road engineering areas and residential building areas).

Since the two types of data vary greatly in monitoring time coverage, only one month of time overlap can be obtained. By selecting 8 relevant feature points (A01-A08) in the I-VIII area, the monitored shape variables of these points in the overlap time are analyzed for difference (see Figure 5). It can be seen from Figure 5 that the two sets of data monitoring results maintained a high correlation between July 2015 and August 2015, and the difference was within 0$\pm 2 \mathrm{~mm}$. Therefore, it can be considered that the monitoring accuracy between the two sets of data in this experiment can reach the millimeter level.

\section{Discussion}

5.1. Deformation Characteristic Point. After determining the scope of the eight subsidence areas, the subsidence feature points (e.g., P1, P2, P3......P27; see in Figure 6) in the area are searched to analyze the deformation characteristics of these feature points on the time series to research the subsidence trend and dynamic development.

5.2. Analysis. From 2013 to 2015, the area I (Yangli StationGushan) was in an irregular state of slow sinking, and the severe subsidence section exceeded $30 \mathrm{~mm}$ even in more than 24 months (see Figure 7); from 2016 to 2018, the overall deformation rate of the area was $-2.9 \mathrm{~mm} /$ year, which was relatively stable. Through data review, it was found that the construction of road works caused the destruction of geological soft soil layers, resulting in the occurrence of staged settlement effects. From Figure 7, the deformation evolution of the feature points in the time series could be found. The feature point had a stepped sedimentation effect before February 2014, and, after this time node, it was oscillating and sinking. It could be considered that before this time node, the road engineering was in the foundation pit 


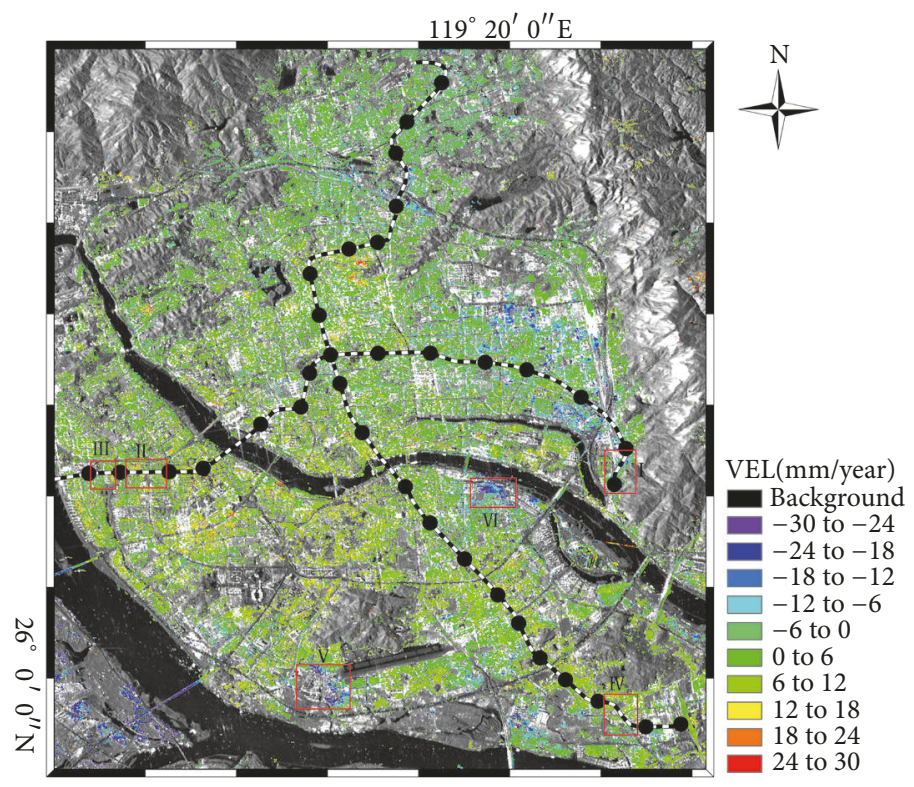

(a)

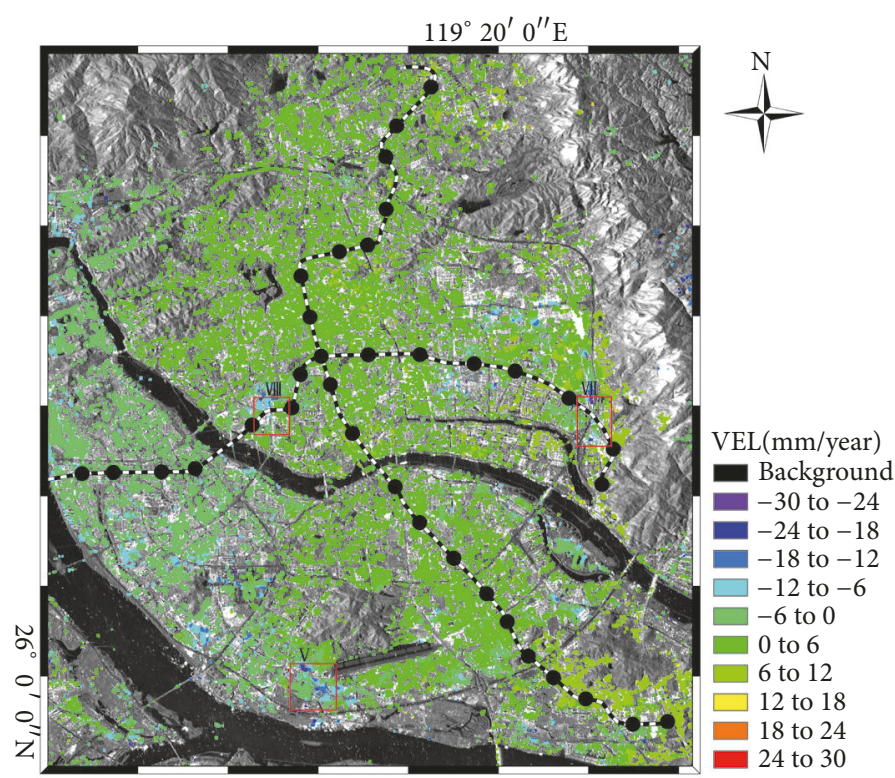

(b)

FIGURE 3: Mean displacement velocity map over the study area derived by SBAS-InSAR technique. (a) reflects the LOS velocity of the Fuzhou downtown in 2013-2015, while (b) reflects the LOS velocity of the Fuzhou downtown in 2015-2018. The red rectangles indicate the area in which violent subsidence takes place (I-VIII). The local deformation map after enlargement can be seen in Figure 6.

pumping construction, which caused the stagnation of the soft soil layer on the surface. After that, the surface was in the recovery phase. However, due to irreversible damage to the surface soil structure, a certain degree of sinking effect will still occur.

From 2013 to February 2014, the area II (JinshanHongwan) experienced continuous subsidence with a settlement of up to $20 \mathrm{~mm}$, and, after February 2014, it showed periodic uplift and settlement deformation rate of +1.6 $\mathrm{mm} /$ year (see Figure 8). It is speculated that the reason for the settlement in the area was the pumping of groundwater, and the periodic uplift and settlement were caused by seasonal rainfall.

Area III (Hongwan-Juyuanzhou) from 2013 to 2015 was between $-10 \mathrm{~mm}$ and $-20 \mathrm{~mm}$, and the main settlement occurred before January 2015 (see Figure 9). The subway construction plan showed that the Juyuanzhou site was in the fence construction state around January 2015. It could be 


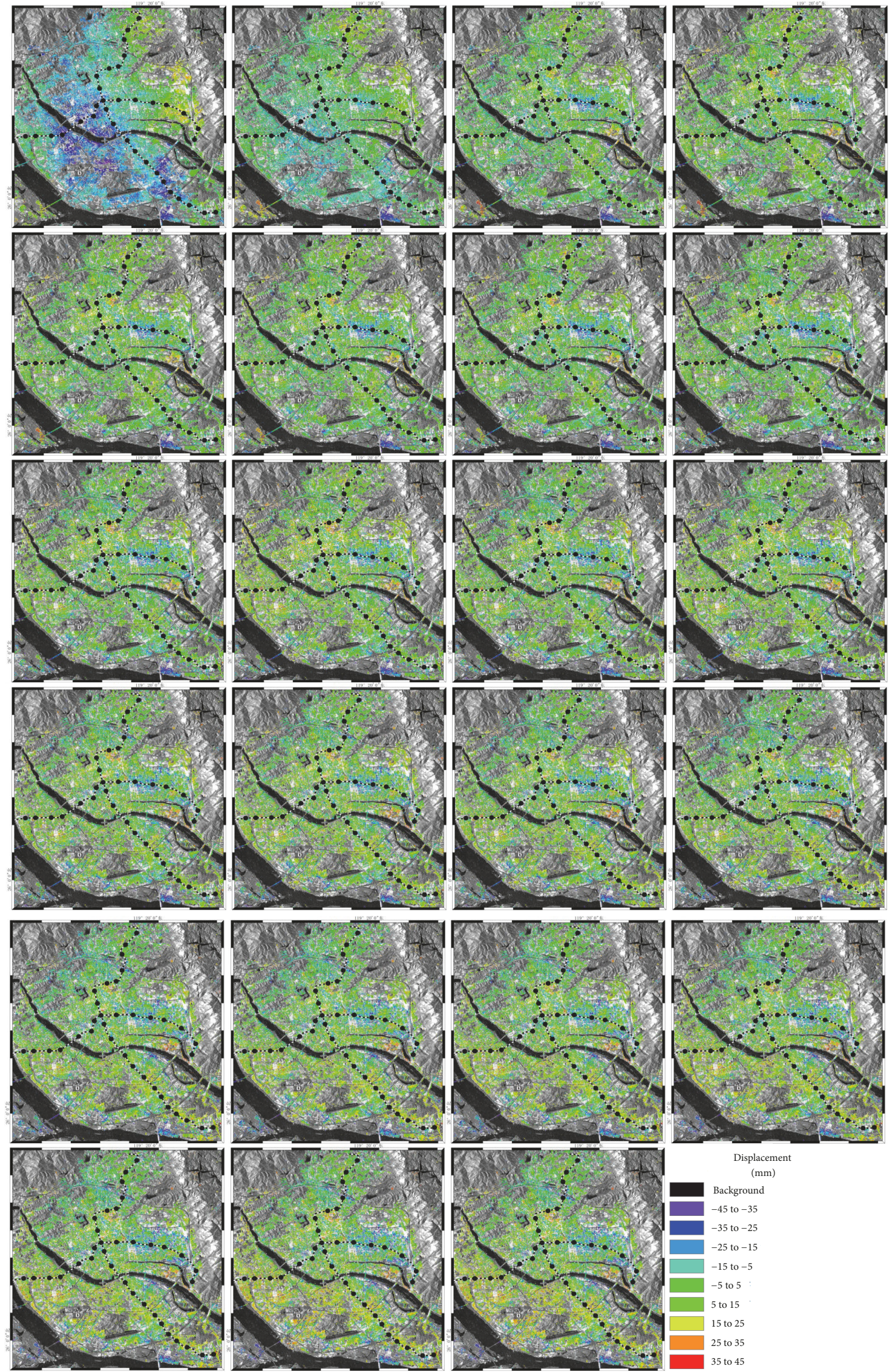

(a)

Figure 4: Continued. 


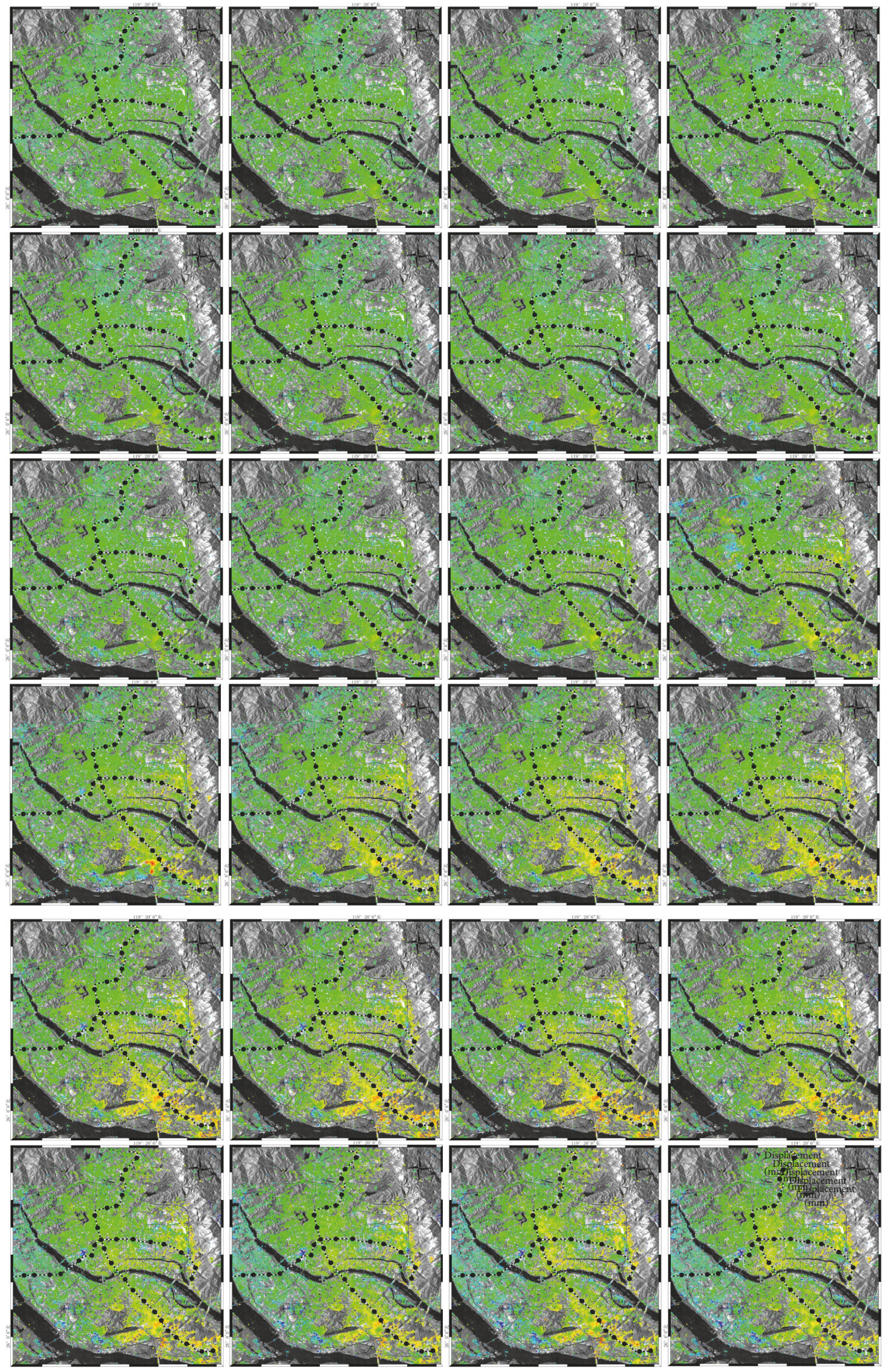

FIgURE 4: Continued. 

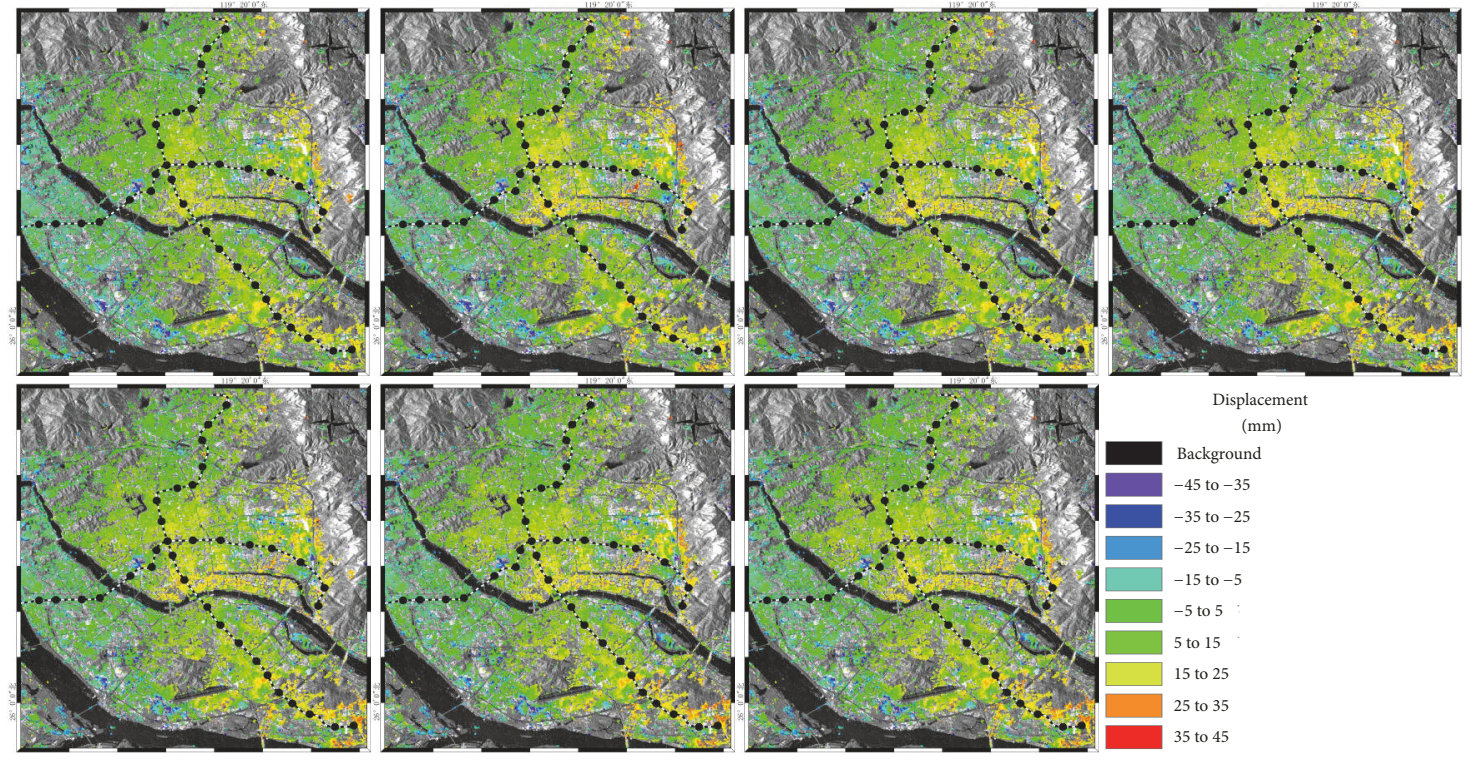

(b)

FIGURE 4: Interferograms of SBAS-InSAR in study area. (a) describes the time-series displacement in Fuzhou downtown in 2013-2015, and (b) shows the long-term subsidence in Fuzhou downtown in 2015-2018.

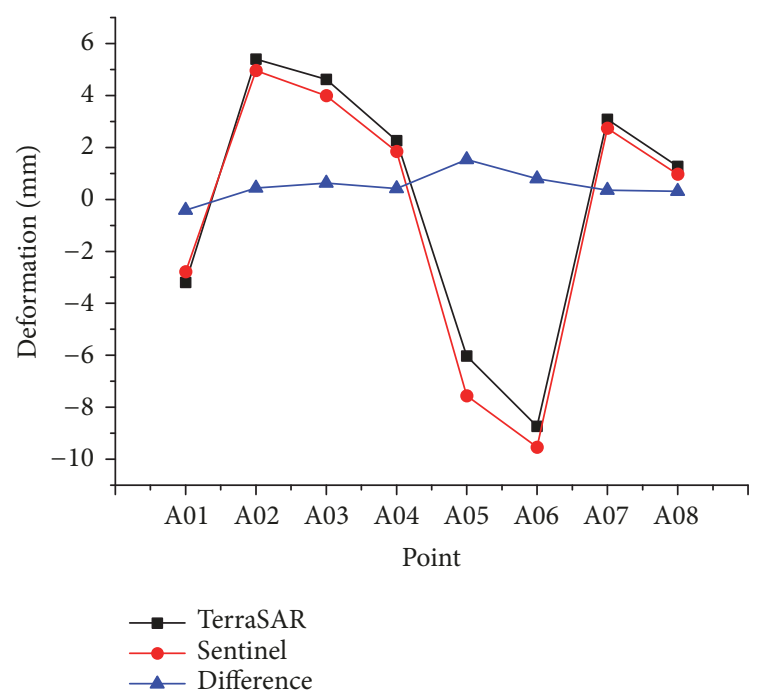

FIgure 5: Analysis of TerraSAR data and Sentinel data shape variables from July 2015 to August 2015.

reasonably considered that the excavation of the foundation pit destroyed the stable state of the nearby soil layer, resulting in uneven settlement.

From 2013 to 2015, the area IV (Lulei-Triangle City) evolved between $0 \mathrm{~mm}$ and $-30 \mathrm{~mm}$, and the overall settlement trend was very consistent, which was slow settlement (see Figure 10). The deformation rate of this interval is -1.5 $\mathrm{mm}$ /year after 2015 and was stable. During the monitoring period, the interval was in the construction phase, and the regional settlement characteristics were very close.

The sedimentation rate values of the area $\mathrm{V}$ between 2013 and 2015 and 2015 to 2018 exceeded $8 \mathrm{~mm} /$ year. The cumulative settlement in the region between 2013 and 2015 was between $-15 \mathrm{~mm}$ and $-65 \mathrm{~mm}$, and between 2015 and 2018 it was between $-45 \mathrm{~mm}$ and $-80 \mathrm{~mm}$. It was worth noting that the regional settlement characteristics were analyzed from the geographical distribution of the feature points. The settlement amplitude of the feature points in the northeast direction was generally larger than that of the southwest direction feature points. From 2013 to 2015, the settlement of P13 and P14 was larger than that of P15; between 2015 and 2018, the settlement of P20 and P21 was also larger than that of P19 (see Figure 11).

In summary, it could be considered that the settlement trend of the area $\mathrm{V}$ was from the southwest to the northeast, and the subsidence area is further increased.

After investigation, it was found that the area $\mathrm{V}$ belongs to the construction scope of the Yixu Highway Project. The excavation of the road works disturbed the structural stability of the soft soil layer and caused the influence of land subsidence. Moreover, with the segmental advancement of road engineering, the scope of settlement would be further shifted and expanded.

The sedimentation rate in the area VI was the largest in all regions, reaching $-12.2 \mathrm{~mm} /$ year between 2013 and 2015, and the cumulative deformation between $-25 \mathrm{~mm}$ and -60 $\mathrm{mm}$ (see Figure 12). The most serious settling funnel was formed at Longhua Apartment, where ground subsidence occurring during this period was confirmed. This was closely related to the construction of the project near the apartment. After 2015, the settlement trend would gradually stabilize and there would be no longer the impact of large-scale settlement disasters.

The accumulative subsidence of area VII (GushanShangyang) from 2015 to 2018 is between $-40 \mathrm{~mm}$ and $60 \mathrm{~mm}$, and the main settlement occurred after April 2016 (see 

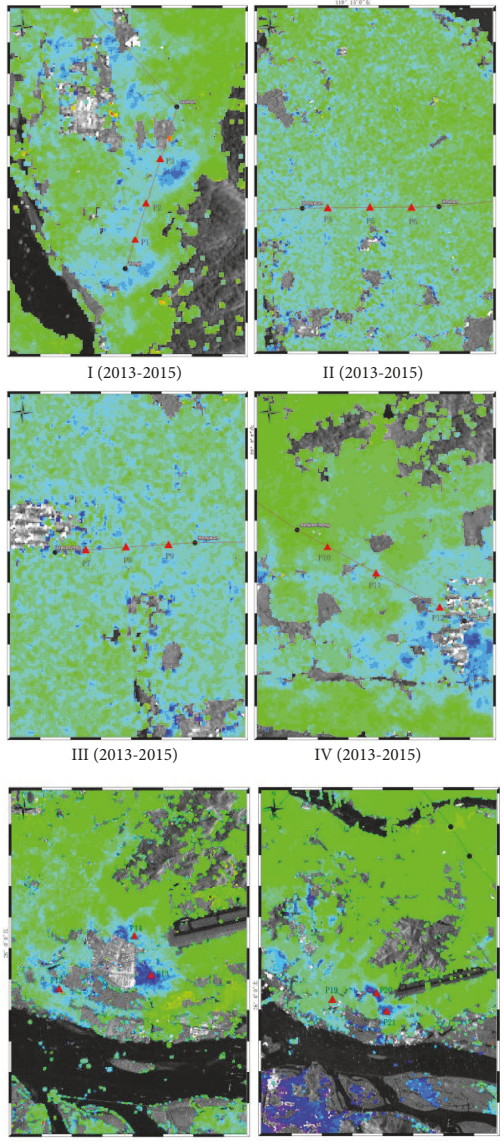

$\mathrm{V}(2013-2015)$

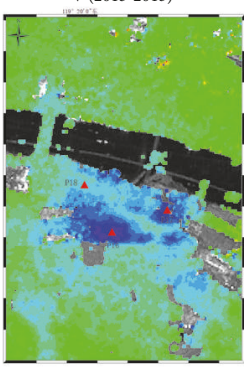

VI (2013-2015)

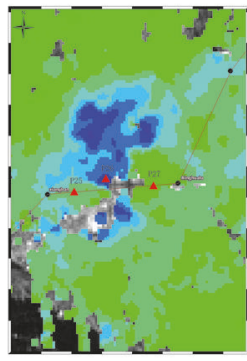

VIII (2015-2018)

FIGURE 6: Location of the selected deformation point on the deformation map (I-VIII).

Figure 13). This section started construction in February 2017, and the regional settlement node as in good agreement with the time. The Shangyang apartment was located on the side of the Shangyang station, and the settlement disaster of the residential building has been affected.

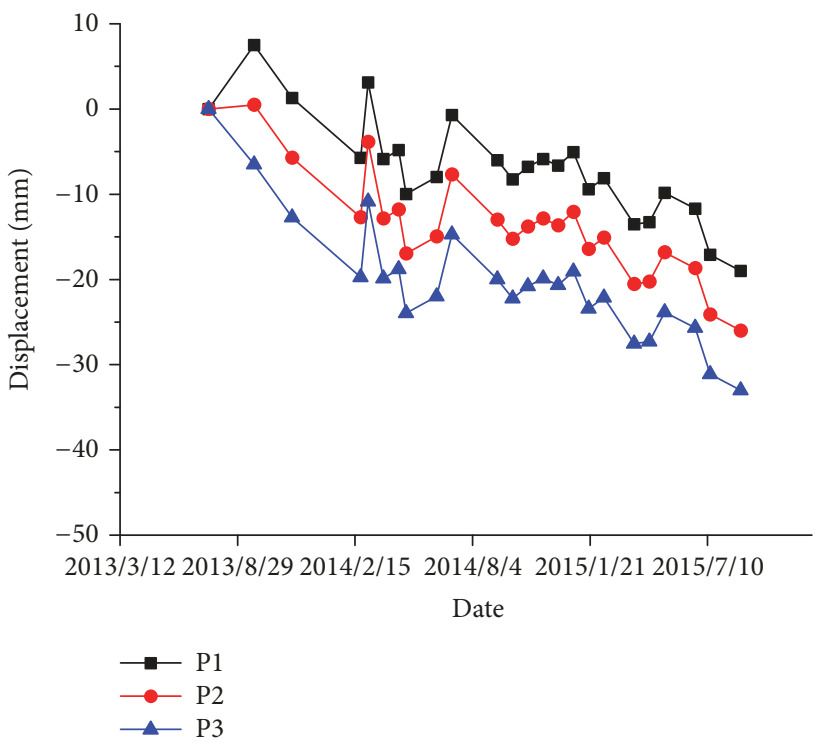

FIGURE 7: The figure status of the time-series displacement of P1, P2, and $\mathrm{P} 3$ within rectangle $\mathrm{I}$.

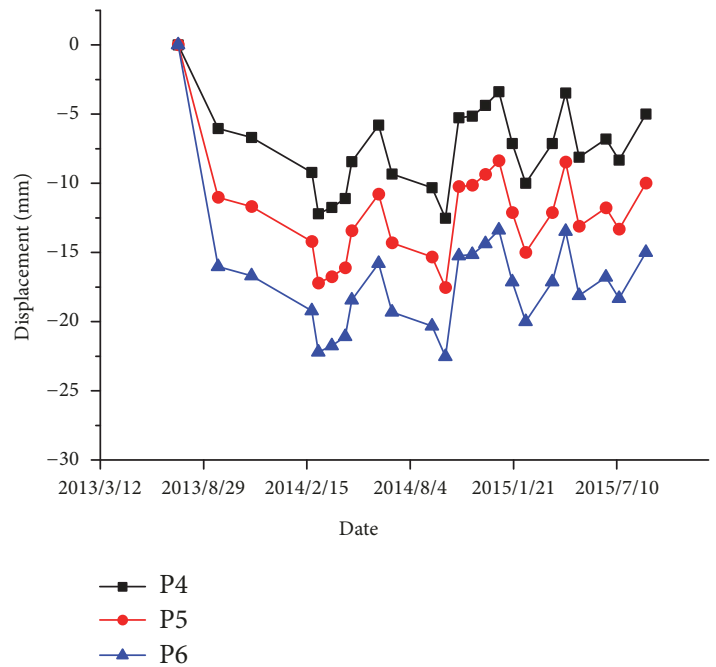

FIGURE 8: The figure status of the time-series displacement of P4, P5, and $\mathrm{P} 6$ within rectangle II.

The deformation rate of area VIII reached $-7.4 \mathrm{~mm} /$ year from 2015 to 2018, and the subsidence point was mainly located at the intersection next to the metro internal. The settlement characteristic points showed that the cumulative settlement of this crossroads was between $-30 \mathrm{~mm}$ and $50 \mathrm{~mm}$, and it would continue to increase after August 2016 (see Figure 14). The crossroads have collapsed badly in 2017.

In summary, this leads to the following inference:

(1) The areas VII and VIII belonged to the subway line of line 2, and the shield construction in the subway section caused the loss of the surface soil layer and the structural damage of the soil around the tunnel caused the sedimentation effect.

(2) The area V belonged to the road construction area. The foundation pit excavation of the road construction destroyed 


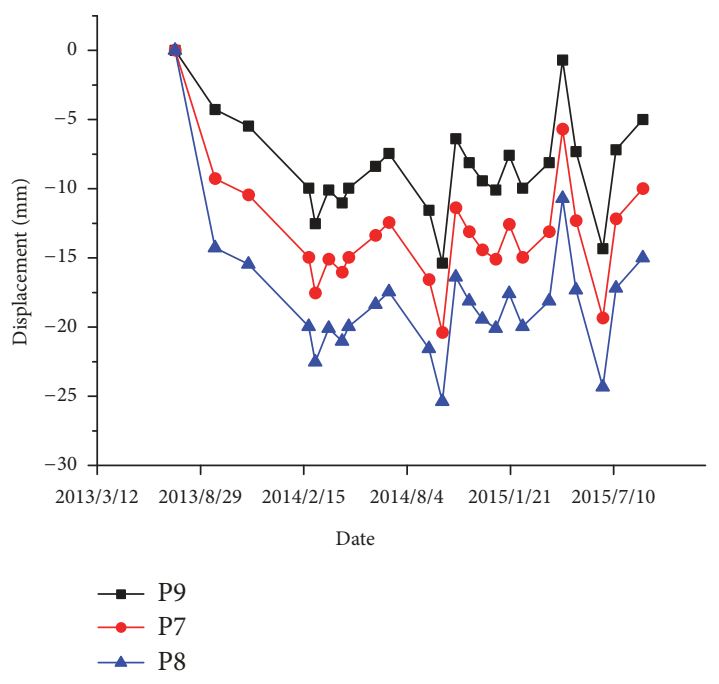

Figure 9: The figure status of the time-series displacement of P7, P8, and P9 within rectangle III.

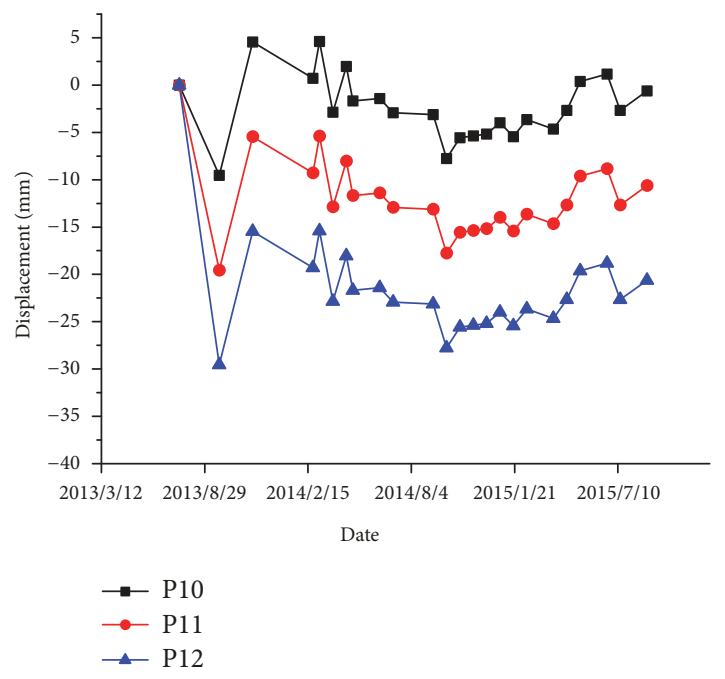

FIgURE 10: The figure status of the time-series displacement of P10, P11, and P12 within rectangle IV.

the stable state of the groundwater layer, and the soil layer near the foundation pit also had the effect of sinking. The settlement effect of the Nanmendou subway station was mainly due to the excessive load.

(3) The subway construction period was long, and the use of a large amount of groundwater in irregular conditions would cause surface subsidence. When the construction was completed, the sedimentation rate was obviously reduced, but the settlement was still present, which takes time from the consolidation of the rock and soil.

\section{Conclusion}

In this experiment, the land deformation of Fuzhou urban area from 2013 to 2018 was successfully performed by applying SBAS-InSAR technology combined with two different

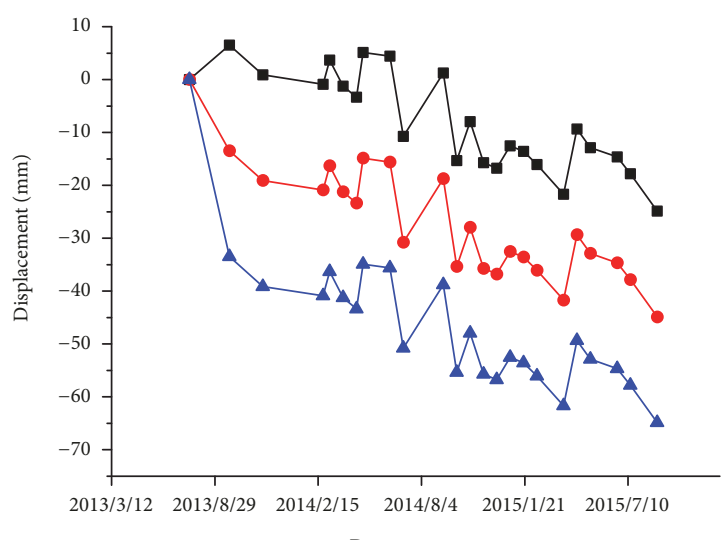

Date

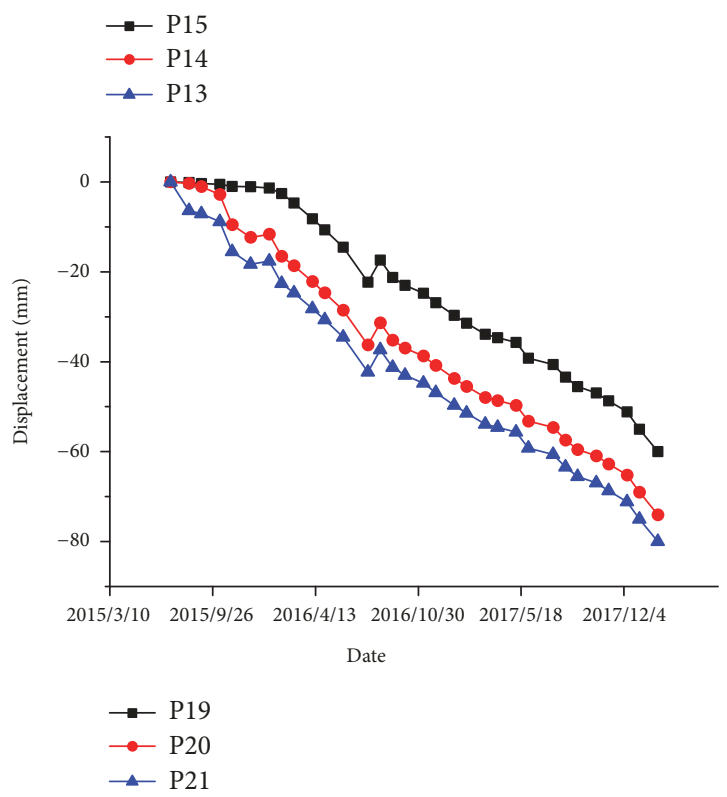

FIGURE 11: The figure status of the time-series displacement of P13, P14, P15, P19, P20, and P21 within rectangle V.

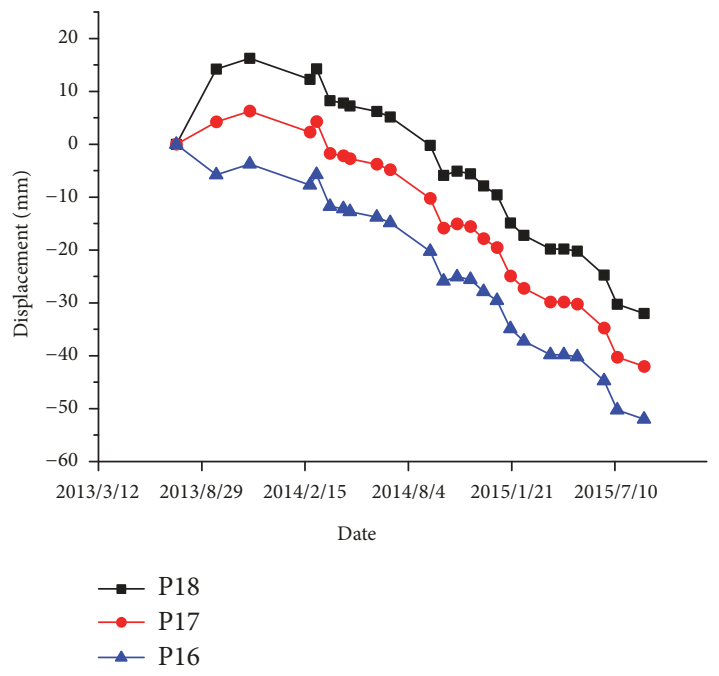

FIGURE 12: The figure status of the time-series displacement of P16, $\mathrm{P} 17$, and P18 within rectangle VI. 


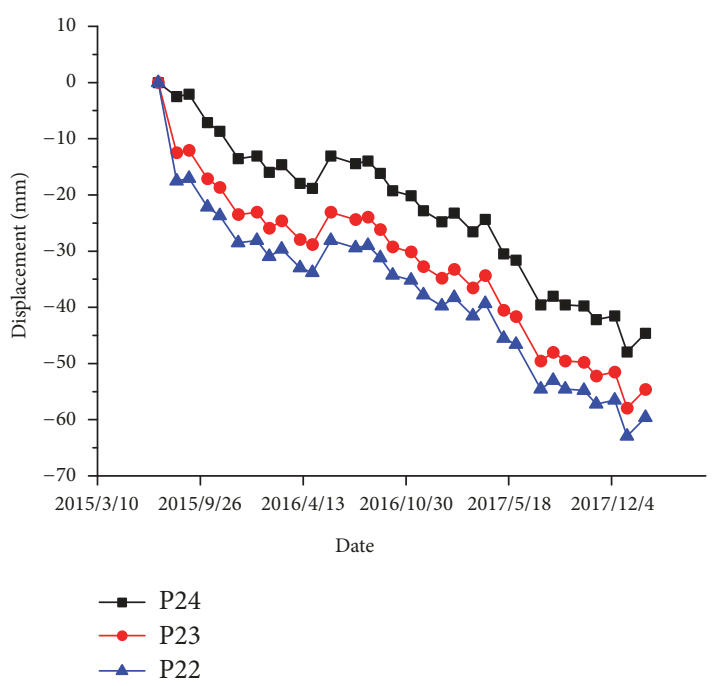

FIgURE 13: The figure status of the time-series displacement of P22, P23, and P24 within rectangle VII.

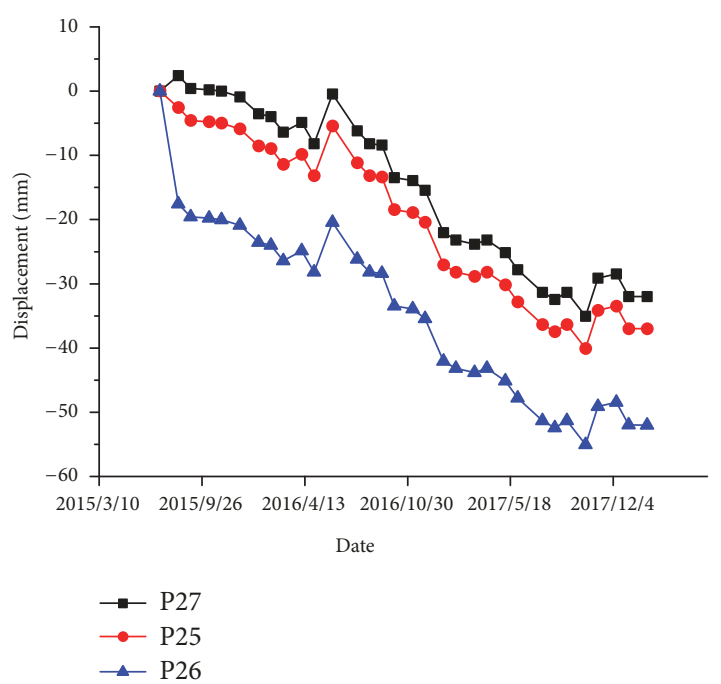

FIGURE 14: The figure status of the time-series displacement of P25, $\mathrm{P} 26$, and P27 within rectangle VIII.

radar satellite data (TerraSAR and Sentine-1). By analyzing the difference between the two datasets of results in the overlap time, the data maintains a high degree of correlation, and the monitoring accuracy between them reaches the millimeter level.

Through the method of time series analysis, the influences and development trends of various subsidence areas were discussed, some stable deformation areas were eliminated, and some potential subsidence disaster areas were also discovered, thereby preventing the occurrence and expansion of subsidence disasters. Among them, the settlement of the areas VII and VIII was caused by the shield construction, which has great reference significance for the future subway project. The settlement of the area $\mathrm{V}$ was caused by the excessive load. Besides, excessive use of groundwater in construction projects requires timely prevention and control measures and is prone to disasters. In summary, the feasibility and practicability of SBAS-InSAR technology in urban building deformation monitoring can be one of the convenient and effective monitoring methods for urban construction and maintenance.

\section{Data Availability}

The DEM AW3D30 download valid link is https://www.eorc .jaxa.jp/ALOS/en/aw3d30/data/index.htm, ID: 2111709052@ mail2.gdut.edu.cn, Password: aw3d30. The Sentinel-1 data used to support the findings of this study may be released upon application to the account (https://scihub.copernicus .eu/dhus/\#/home), which can be contacted via email. The TerraSAR data used to support the findings of this study were supplied by DLR under license and so cannot be made freely available. Requests for access to these data should be made to DLR. The authors obtained TerraSAR data by applying quota of scientific research data.

\section{Conflicts of Interest}

The authors declare that there are no conflicts of interest regarding the publication of this paper.

\section{Acknowledgments}

This work was supported by the Science and Technology Plan Project in Fujian Province (grant No. 2017Y3004) and by the National Natural Science Foundation of China (Grant Nos. 41204012 and 41674006). We wish to thank the European Space Agency (ESA) for arranging the Sentinel data and Japanese Aerospace Agency (JAXA) for providing "ALOS World 3D - 30m" data.

\section{References}

[1] Y. Yue_Ping, Z. Zuo_Chen, and Z. Kai_Jun, "Land subsidence and countermeasures for its prevention in China," The Chinese Journal of Geological Hazard and Control, vol. 16, no. 2, pp. 1-8, 2005.

[2] S. Dong, S. Samsonov, H. Yin, S. Ye, and Y. Cao, "Timeseries analysis of subsidence associated with rapid urbanization in Shanghai, China measured with SBAS InSAR method," Environmental Earth Sciences, vol. 72, no. 3, pp. 677-691, 2014.

[3] Q. Luo, D. Perissin, H. Lin, Y. Zhang, and W. Wang, "Subsidence monitoring of tianjin suburbs by TerraSAR-X persistent scatterers interferometry," IEEE Journal of Selected Topics in Applied Earth Observations and Remote Sensing, vol. 7, no. 5, pp. 16421650, 2014

[4] H. Sun, Q. Zhang, C. Zhao, C. Yang, Q. Sun, and W. Chen, "Monitoring land subsidence in the southern part of the lower liaohe plain, China with a multi-track PS-InSAR technique," Remote Sensing of Environment, vol. 188, pp. 73-84, 2017.

[5] J. K. Hole, C. J. Bromley, N. F. Stevens et al., "Subsidence in the geothermal fields of the taupo volcanic zone, New Zealand from 1996 to 2005 measured by InSAR," Journal of Volcanology and Geothermal Research, vol. 166, no. 3-4, pp. 125-146, 2007. 
[6] H. Wang, L. Jia, H. Steffen et al., "Increased water storage in North America and Scandinavia from GRACE gravity data," Nature Geoscience, vol. 6, no. 1, pp. 38-42, 2013.

[7] Y. Yan, M. P. Doin, P. López-Quiroz et al., "Mexico city subsidence measured by InSAR time series: joint analysis using PS and SBAS approaches," IEEE Journal of Selected Topics in Applied Earth Observations and Remote Sensing, vol. 5, no. 4, pp. 1312-1326, 2012.

[8] H. A. Zebker, P. A. Rosen, and S. Hensley, "Atmospheric effects in interferometric synthetic aperture radar surface deformation and topographic maps," Journal of Geophysical Research: Solid Earth, vol. 102, no. 4, pp. 7547-7563, 1997.

[9] H. A. Zebker and J. Villasenor, "Decorrelation in interferometric radar echoes," IEEE Transactions on Geoscience and Remote Sensing, vol. 30, no. 5, pp. 950-959, 1992.

[10] O. Mora, J. J. Mallorqui, and A. Broquetas, "Linear and nonlinear terrain deformation maps from a reduced set of interferometric SAR images," IEEE Transactions on Geoscience and Remote Sensing, vol. 41, no. 10, pp. 2243-2253, 2003.

[11] A. Hooper, H. Zebker, P. Segall et al., "A new method for measuring deformation on volcanoes and other natural terrains using InSAR persistent scatterers," Geophysical Research Letters, vol. 31, no. 23, pp. 1-5, 2004.

[12] S. Usai, "A least squares database approach for SAR interferometric data," IEEE Transactions on Geoscience and Remote Sensing, vol. 41, no. 4, pp. 753-760, 2003.

[13] R. Lanari, O. Mora, M. Manunta, J. J. Mallorquí, P. Berardino, and E. Sansosti, "A small-baseline approach for investigating deformations on full-resolution differential SAR interferograms," IEEE Transactions on Geoscience and Remote Sensing, vol. 42, no. 7, pp. 1377-1386, 2004.

[14] M. Mçetois, A. Socquet, C. Vigny et al., "Revisiting the North Chile seismic gap segmentation using GPS-derived interseismic coupling," Geophysical Journal International, vol. 194, no. 3, pp. 1283-1294, 2013.

[15] E. Chaussard, S. Wdowinski, E. Cabral-Cano, and F. Amelung, "Land subsidence in central Mexico detected by ALOS InSAR time-series," Remote Sensing of Environment, vol. 140, pp. 94106, 2014.

[16] P. Berardino, G. Fornaro, R. Lanari, and E. Sansosti, "A new algorithm for surface deformation monitoring based on small baseline differential SAR interferograms," IEEE Transactions on Geoscience and Remote Sensing, vol. 40, no. 11, pp. 2375-2383, 2002.

[17] C. Zhao, Q. Zhang, W. Zhu, and Z. Lu, "Monitoring on Xian ground fissures deformation with TerraSAR-X data," Geomatics and Information Science of Wuhan University, vol. 37, no. 1, pp. 81-85, 2012.

[18] A. J. Hooper, Persistent Scatter Radar Interferometry for Crustal Deformation Studies and Modeling of Volcanic Deformation, 2006. 


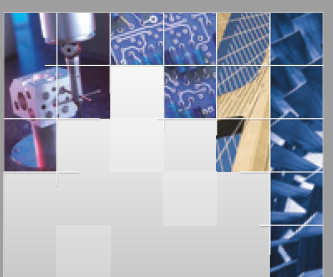

\section{Enfincering}
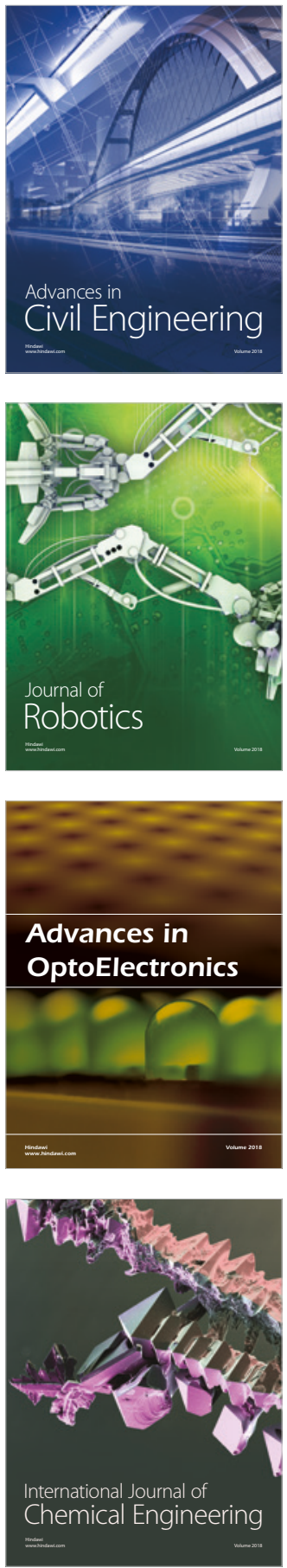

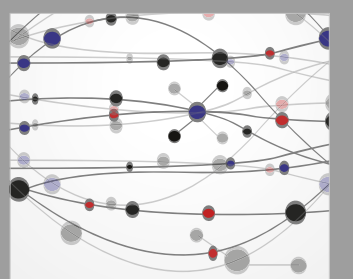

\section{Rotating \\ Machinery}

The Scientific World Journal

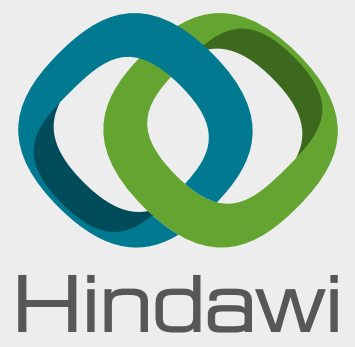

Submit your manuscripts at

www.hindawi.com
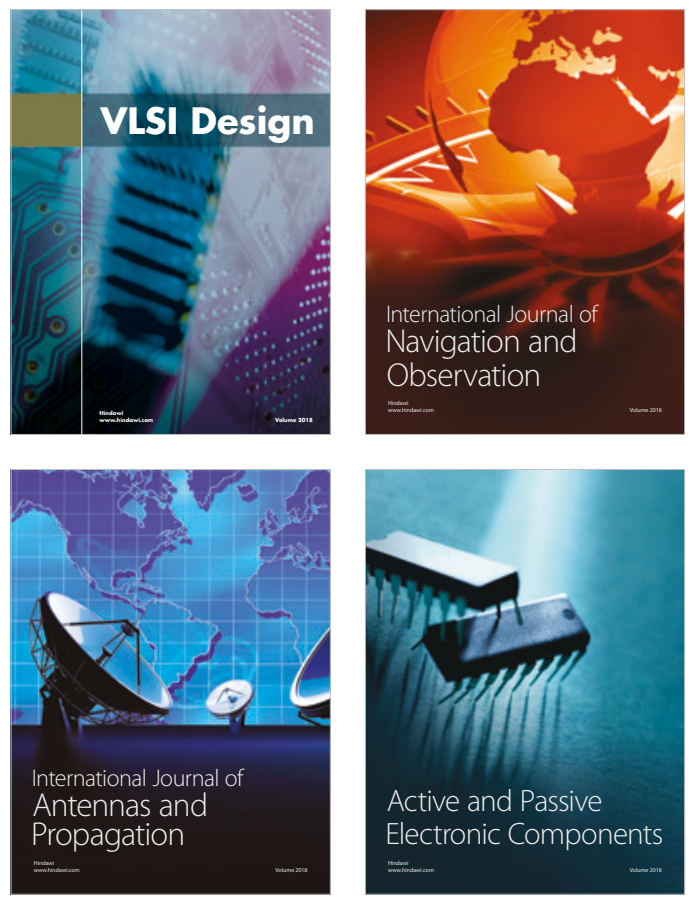
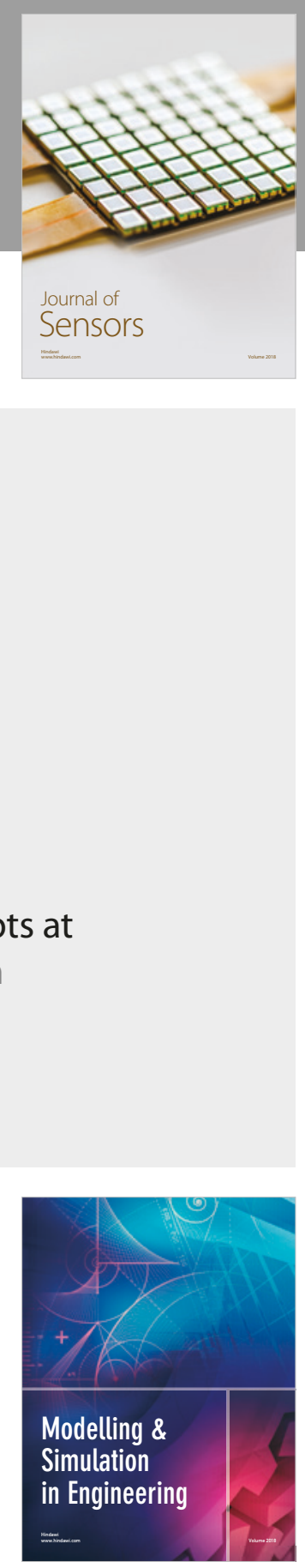

\section{Advances \\ Multimedia}
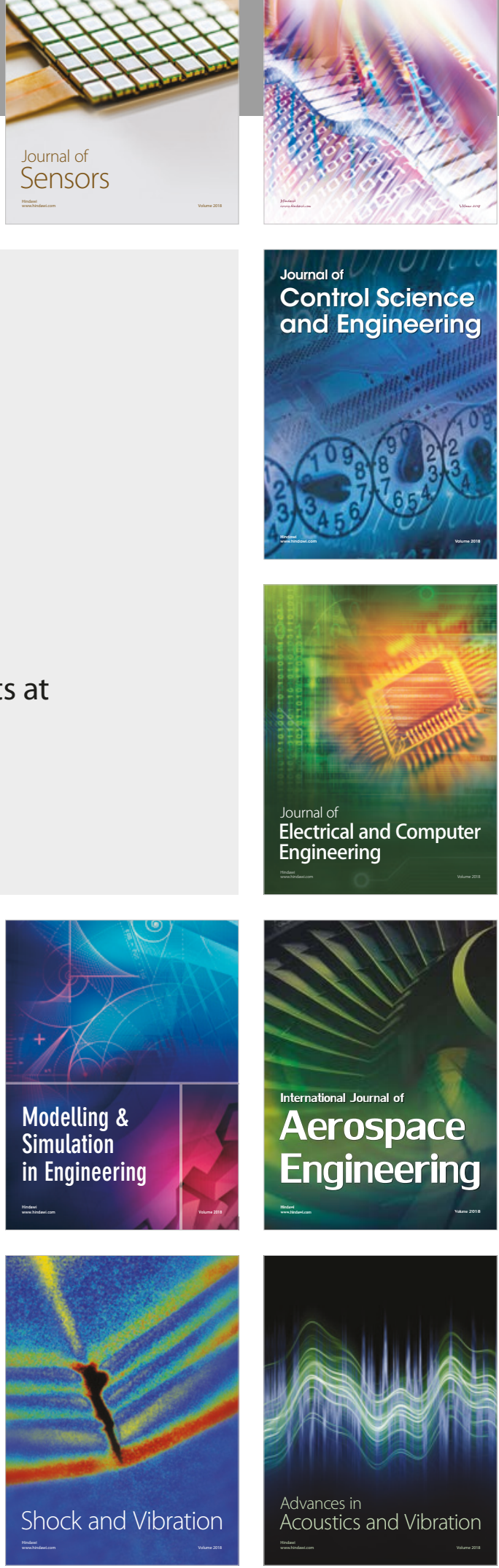